\title{
Effectiveness of Read-aloud Instruction on Motivation and Learning Strategy among Japanese College EFL Students
}

\author{
Katsumasa Shinozuka ${ }^{1}$, Setsue Shibata ${ }^{2} \&$ Yumiko Mizusawa ${ }^{3}$ \\ ${ }^{1}$ Faculty of of Health and Sports Science, Juntendo University, Japan \\ ${ }^{2}$ Department of Modern Languages and Literature, California State University, Fullerton, United States \\ ${ }^{3}$ Faculty of Science and Technology, Keio University, Japan \\ Correspondence: Setsue Shibata, Department of Modern Languages and Literatures, California State University, \\ Fullerton, United States. E-mail: sshibata@fullerton.edu
}

Received: September 5, 2016

Accepted: March 2, 2017 Online Published: March 6, 2017

doi: $10.5539 /$ elt.v10n4p1

URL: http://doi.org/10.5539/elt.v10n4p1

\begin{abstract}
Poor English performance among Japanese college EFL students has often been explained by grammar-translation and lecture-memorization instruction. This study investigated the effectiveness of a recently designed teaching method, namely, "The read-aloud instruction package," which consists of four major activities: Slash/chunked reading practice (S/CRP), repeated read-aloud practice (RRAP), cloze test, and simultaneous read-aloud and write-out practice (SRAWOP). The study also examined how EFL college students' motivation to learn English and their choice of EFL learning strategies changed after intensive three-month' instruction using these methods. Thirty-two participants with an elementary level of English proficiency completed a pretest and posttest using the TOEIC Bridge ${ }^{\circledR}$, Strategy Inventory for Language Learning (SILL) and a motivation survey. Results indicated that the participants' score on the posttests on the TOEIC Bridge ${ }^{\circledR}$ improved significantly, but no change was found in their motivation. As to EFL learning strategy, the study found that the participants used more mental processes but less learning with others strategy after the instruction. The article discusses some possible explanations of the effectiveness of the read-aloud instruction package from cognitive and neuro-linguistic perspectives.
\end{abstract}

Keywords: English as a foreign language, Japanese learners, learner's motivation, learning strategy, read-aloud instruction package

\section{Introduction}

English is considered the most important international lingua franca in the world and many efforts have been made in the past decades to improve EFL students' English proficiency in various aspects (e.g., professional training, teaching strategy, curriculum development, and creating better instructional materials). More recently, in order to improve overall English skills in Japan, given this age of globalization, English instruction has been implemented from the third year of primary school (Ministry of Education, Culture, Sports, Science and Technology in Japan, 2013). However, despite these efforts, the English language proficiency of Japanese college students is still not satisfactory. The English Proficiency Index (EPI) indicated that Japanese adults have not improved their English in the past six years, while other Asian countries, most notably Indonesia and Vietnam, have made a significant progress (Japan Today, 2014). The EPI also indicated that Japan ranked 26th out of 65 countries in global English proficiency in spite of being a far wealthier and more developed country. "Japan is struggling to teach English for use in a competitive global economy" (Japan Today, 2014). Educational Testing Service (ETS, 2010) also revealed that the average score of Japanese college students measured on the TOFEL iBT ${ }^{\circledR}$ (internet-based test) in 2010 was considerably low, and was ranked 27th out of 30 Asian countries. International English Language Testing System (IELTS, 2015) also showed that the Japanese academic module candidates' mean band score in 2012 ranked 14th among 15 Asian countries.

Poor performance in English among Japanese college EFL students has often been attributed to pedagogical issues in teaching methods which are still considered teacher-centered (Diaz-Maggioli, 2004), or focused on grammar-translation method (Smith, 1981). In addition, poor English proficiency of Japanese students has been associated with linguistic distance (LD) influencing in the considerably low results in TOEFL and IELTS. This suggestion is supported by Chiswick and Miller (2004) who analyzed that LD between English and Japanese 
languages is farther compared to distance between English and Afrikaans Norwegian, Rumanian and Swedish.

Seeking more effective teaching methods has been one of the main goals in the field of TESOL/ESL in Japan, which motivated Shinozuka, Mizusawa, and Shibata (2014) to design the "read-aloud instruction package." This series of instructional methods emphasizes repeated read-aloud practices which are combined with other classroom activities such as slash/chunked-reading, cloze-test, and simultaneous read-aloud and write-out practice. In their study, Shinozuka et al. (2014) found that their instruction package improved students' EFL proficiency after three months of instruction. However, there was still a need to investigate the effectiveness of these instruction practices with a different participant group in order to determine further support for the findings of Shinozuka et al. (2014). This study also explored the influence of these instructional methods, if any, on student motivation and learning strategies, two significant factors for successful language learning.

\section{Literature Review}

\subsection{Read-aloud Instruction Package}

To improve students' EFL proficiency, Shinozuka et al. (2014) designed the read-aloud instruction package for Japanese college EFL students whose English proficiency was at the elementary level, based on TOEIC IP (Institutional Program) scores as a placement test conducted by the college of the participants (Shinozuka et al., 2014). Rationales for effectiveness of each of the four components of instruction are discussed below.

\subsubsection{Slash/chunked Reading Practice (S/CRP)}

Read-aloud practice involves "chunking," which involves taking a large text passage or individual words and breaking them into smaller chunks. Much previous research has found that S/CRP increases reading speed (Ellis, 2003; Newell, 1990; Nishida, 2009; Ohtagaki \& Ohmori, 1991; Tan \& Nicholson, 1997), and improves reading fluency and comprehension of struggling students in reading (Jones, 2012; Kadota, 1982; Kiroglu \& Demirel, 2012; Kowal, O'Cannel, O'Brien, \& Bryant, 1975). Struggling readers, on the other hand, often do not understand where a meaningful phrase ends, and they do not understand the whole sentence (Ransinki et al., 2005), whereas advanced readers are able to read a text by chunking it into meaningful phrase units effortlessly because they understand the sentence structure. They are not only able to process reading materials on a surface basis but comprehend the deeper meanings of the materials. In other words, successful readers can skim and scan reading materials, at the same time they can read them in a more in-depth way (Ransiki et al., 2005). S/CRP helps the readers comprehend syntactical sentence structure (Foder, Bever, \& Garrett, 1974; Schreiber \& Read, 1980). Casteel (1988) investigated if S/CRP would be beneficial for improving the reading skills of high school students with learning disability. In comparing the experimental and the control groups, he found that the chunked reading group significantly improved their reading skills. Furthermore, the effectiveness of S/CRP is also explained from a neuroscientific perspective (i.e., the working memory) system in the brain (e.g., Gilbert, Boucher, \& Jemel, 2014; Just \& Carpenter, 1987). Hook and Jones (2002) stated that S/CRP might be used for students with dyslexia. Because of these positive findings from previous studies, S/CRP was included as a teaching method in the read-aloud instruction package in this study.

\subsubsection{Repeated Read-Aloud Practice (RRAP)}

Developing fluency and automaticity in word and syntactic processing are indispensable elements (Grabe \& Stroller, 2002). Similarly, Stoddard, Valcante, Sindelar, and Algozzine (1993) state that repeated oral reading practice may contribute to increasing both fluency and automaticity in reading. In support of this, Schwanenflugel, Harnishleger, and Stowe (1998) found that oral reading practice could lead to improving decoding speed and developing prosody in reading, as well as reading comprehension skills. Chang (2012) examined the effects of repeated oral reading on 35 college students in Taiwan, and found that it can be beneficial to increasing reading comprehension skills. In addition, Fuchs, Fuchs, and Hosp (2001) found that the correlations between oral reading fluency and comprehension were very high $(r=.81$ to .90$)$, which concurred with other studies (see, for example, Miyasako, 2008).

\subsubsection{Cloze Tests}

Cloze tests are similar to fill-in-the-blank tests, and have a relatively long history established by Taylor (1953) for various purposes. Since the validity and reliability of the test were supported by numerous researchers (e.g., Darnell, 1968; Jongsma, 1971; Oller, 1972), the tests have been used as a major measurement of overall language proficiency since the 1970s (see Jongsma, 1971; Oller, 1976; Robinson, 1972). There are some opponents who are skeptical of the effects of cloze tests, claiming that the tests only measure the ability to make localized connections in the texts (Alderson, 1980; Porter, 1983; Bachman, 1982 and 1985). However, Alderson (1979) and Readance, Balwin, Bean, and Dishner (1980) state that the cloze tests are a particularly valid measure of reading 
comprehension as well as text readability for native speakers of English, and are one of the most useful tools for assessing reading comprehension level, learning process, and accurate grammatical knowledge of EFL learners. For nonnative English speakers, it is considered as a reliable measure of comprehensive L2 language proficiency (Bialystok \& Howard, 1979; Aitken, 1977; Oller, 1976).

\subsubsection{Simultaneous Read-Aloud and Write-Out Practice (SRAWOP).}

Since Kunihiro (1970) introduced this method for Japanese EFL learners in the early 1970s, it has become one of the important teaching methods of English in Japan. This resembles transcription, but EFL students are required to read the passage verbally themselves instead of a third person. While reading aloud has been a common practice in L2 language classrooms in Japan, simultaneous read-aloud and write-out practice is not, and little research has been conducted which sheds light on this method.

This method has two concepts: the EFL students are supposed to read aloud, and then write down meaningful English sentences and vocalize them simultaneously. The method uses three major sensory motor elements simultaneously, i.e., visual (visual input of the reading materials), kinetic (read-aloud, verbal output), auditory (listen to one's own reading through bone conduction (Note 1), and kinetic again (handwriting/writing out). It is suggested that using various cognitive sensory motor elements simultaneously promotes better memorization and conservation in long-term memory (LTM), as well as better access to LTM (i.e., recall/retrieve necessary information easily) (e.g., Baddeley, 1986, 1998, 1999; Pontart et al., 2013). Kunihiro (1970) also claims that kinetic exercise, similarly to playing sports, helps to automatize learning. He also states that for elementary level EFL learners, after the critical period (Lenneberg, 1967), repeated reading aloud and writing out are both mandatory in order to acquire L2.

Figure 1 illustrates a simultaneous read-aloud and write-out practice. As the figure indicates, this practice includes the four skills of language (i.e., reading, listening, writing and speaking) with visual and auditory input and oral/ kinetic output.

Input

Visual Input

(Oral reading / reading aloud) $+$

\section{Auditory Input (Listening to his/her own voices through bone conduction)}

Simultaneous

Output

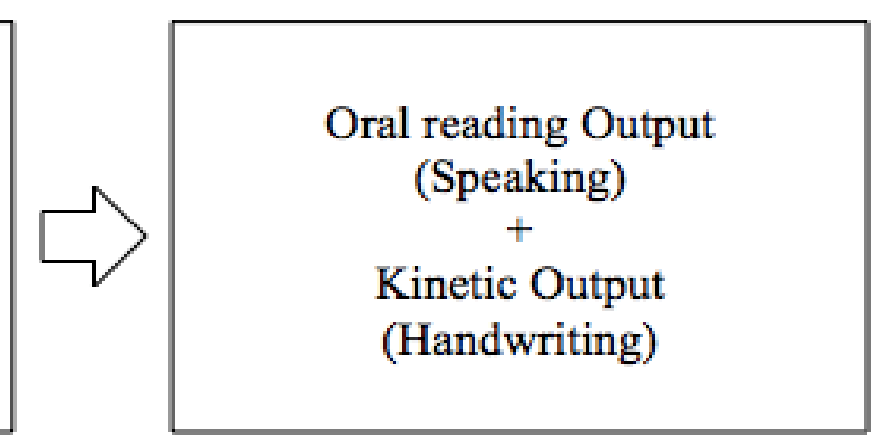

Figure 1. Model of simultaneous reading-aloud and writing-out practice

\subsection{Motivation of EFL Learners}

Learner motivation has been a popular topic for many ESL/EFL researchers since it is claimed to play an important role in developing a second or foreign language. Gardner and Lambert (1972) were the first scholars who classified motivation to learn a foreign language as instrumental and integrative (see also Gardner, 1985a, 1985b). They found that integrative motivation was positively related to higher proficiency than instrumental motivation. However, there are a number of studies that found instrumental motivation was related to higher proficiency rather than integrative motivation (e.g., Au, 1988; Oller, Hudson, \& Liu, 1977). Even though these two categories persist in being the essential components, recent scholars have explored alternative motivation models to explain and accommodate learners' social and cultural backgrounds, and to investigate the relationship between learners' English proficiency and their motivation (Dörnyei, 1994; Oxford \& Shearin, 1994). Ely (1986) found three distinct motivation clusters by using a factor analysis, e.g., integrative, instrumental, and the foreign language requirement. In the Japanese university EFL context, Ayabe, Kano and Ito (1995) identified factors which are not directly related to the purpose of learning a foreign/second language, such as to obtain a good grade and to respond to the expectation from parents and/or others. Yoshida (2009) mentioned that responding to the expectation from parents and/or others is a uniquely important concept in Japanese culture, where traditionally "family" precedes 
"individual" and children have been required to meet parents' expectations. Brown (2004) identified four factors using factor analysis, i.e., personal development, job-related factors, intrinsic interest, and pop-culture related factors. Miyahara et al (1997) compared motivation to learn English among university students in China, Korea, and Japan, and found that integrative motivation of Japanese learners differed from the other two Asian countries. They concluded that Japanese students did not have a strong desire to learn English for the purpose of integrating into English-speaking communities, but have a general positive interest in traveling and communicating with native English speakers. In Yashima's study (2000), it was reported that learners who were both instrumentally and integratively motivated earned higher proficiency.

Motivation is an important factor in learner success as mentioned earlier, and teaching skills to teachers to motivate learners in the classroom is an important part of teaching effectiveness. Dörnyei and Csizer (1998) identified that the environment for learning is one of the components that affects a learner's motivation, and proposed ten specific teaching strategies to motivate language learners based on the survey results of two hundred Hungarian teachers of English. In a study by Hiromori and Tanaka (2006), it was found that five weeks of task-based group presentation activity enhanced the Japanese university EFL learners' intrinsic motivation. Kato (2012) also reported three classroom activities, i.e., reproduction, group work, and shadowing practice, increased the learners' self-autonomy after 14 weeks. Nevertheless, these previous studies used a motivation survey only after the instruction. The current study, therefore, conducted pre and post survey after the instruction to assess whether the instruction (read-aloud instruction package) enhanced student motivation.

\subsection{Learning Strategy and Language Proficiency}

Language learning strategies are generally defined as the EFL learner's consciously chosen tools for active, self-regulated improvement of language learning. There are a number of ways to categorize types of learning strategies (e.g., Purpura, 1997; Gan, Humphreys, \& Hamp-Lyon, 2004; O’Malley, Chamot, Stewner-Manzanares, Kupper, \& Russo, 1985), but “Oxford's (1990) work lays out the most exhaustive hierarchy of learning strategies to date." (Rivera-Mills \& Plonsky, 2007, p. 535).

Oxford (1990) divided the strategies into two major classes: direct and indirect, and then subdivided them into a total of six subgroups. "Indirect" strategies are those that support or manage language learning without directly involving the target language (Oxford, 1990, p. 135). The six subgroups of learning strategies are: (1) Memory strategies for storing and retrieving information, (2) Cognitive strategies for understanding and producing the language, (3) Compensation strategies for overcoming limitations in language learning, (4) Metacognitive strategies for planning and monitoring learning, (5) Affective strategies for controlling emotions, motivation, and (6) Social strategies for cooperating with others in language learning. Memory, Cognitive, and Compensation strategies are under the "direct" strategies category, and Metacognitive, Affective, and Social strategies are under the "indirect."

Many studies have been conducted to establish the relationship between ESL/EFL learning strategies, and the wide range of variables found in learners such as age or school year (e.g., Griffiths, 2003; Oxford \& Ehrman, 1995; Riazi, 2007; Srisupha, 2012), English proficiency (e.g., Baker \& Boonkit, 2004; Ghafournia, 2014; Murray, 2010), cultural background (e.g., Alhaisoni, 2012; Lengkanawati, 2004), motivation (e.g., Oxford \& Nyikos, 1989), and personality traits (e.g., Kaufman et al., 2008; Moldasheva \& Mahmood, 2014). Previous studies also found that more successful ESL/EFL learners tend to make more frequent use of learning strategies overall (e.g., Ghani, Mahfuz, Saad, \& Yusoff, 2014; Akbari, 2003, Green \& Oxford, 1995; Murray, 2010; Wharton, 2000). Some studies also examined the learners' cultural backgrounds. For example, Iranian students used metacognitive strategies the most frequently, followed by cognitive and social, with affective being the least (Pishghadam, 2009). Khamkhien (2010a, 2010b) found that Thai and Vietnamese EFL students used compensation the most, followed by cognitive and metacognitive strategies, while Baker and Boonkit (2004) reported metacognitive, cognitive and compensation were the strategies that more successful Thai students used the most. Murray (2010) found that more advanced Korean learners of English used cognitive and memory strategies more often, and Lai (2009) reported metacognitive and cognitive were the strategies used by advanced Taiwanese learners than less advanced students. Tandoc and Tandoc-Juan (2014) studied the most preferred learning strategies of English among college students in the Philippines. They found those most preferred to be memory strategies for the first-year students, social for the second and third, and affective strategies for the fourth-year students. In the Japanese context, Wakamoto (2000) compared extroverts and introverts regarding their learning strategies of English among English majors. He found that extroverts were more willingly to make mistakes and tried to speak out with few inhibitions. Since extroverts are considered better language learners (e.g., Zafar \& Meenakshi, 2012, p. 36), the author implicated that among Japanese college students, successful learners tended to use more socio-affective strategies. In sum, although some differences were found in subgroups among different ethnic groups, many scholars agree that more successful 
learners use strategies overall more frequently than less successful learners of English.

\subsection{Research Question}

The research question in this study is threefold:

1) Is the read-aloud instruction package effective with different students?

2) Does the read-aloud instruction package influence the student's motivation to learn English?

3) Does the read-aloud instruction package influence the student learning strategy for English?

\section{Methodology}

\subsection{Participants}

The participants were 32 first-year students whose nationality was Japanese, and who studied in the same college located in a suburb of Tokyo, Japan. They were either 18 or 19 years old at the time of this study. None of them had experienced living in a foreign country more than one year. Based on a placement test (TOEIC IP), their English proficiency levels were at an elementary level. Informed written consent was obtained from the participants.

\subsection{The Read-Aloud Instruction Package and Its Effectiveness}

In this study, the reading materials were obtained from the Japan Times ST, available online. We chose some materials which interested the participants such as those about incidents that occur in our daily lives. The average readability of the materials was from 9 to 10 based on the Flesch-Kincaid Grade Level (FKG) and the Colman-Liau Index (CLI). The average word length of the materials was 66 words. By using the above reading materials, the read-aloud instruction package, i.e., slash/chunked reading, reading aloud practice, cloze test and finally simultaneous practice of read aloud and write out were implemented.

The TOEIC Bridge ${ }^{\circledR}$ Test was administered twice to measure English proficiency before (pretest) and after (posttest) three months' intensive read-aloud instruction package. Dependent t-tests were applied to determine if there was a significant difference between pretest and posttest scores using SPSS (version 14) to answer research question part 1).

\subsection{Questionnaires}

Three questionnaires were used in this research: a student background questionnaire, a motivation survey, and a Japanese version of the Strategy Inventory for Language Learning (SILL) (Oxford, 1990), described below.

- Student background questionnaire. This questionnaire collected the following data: age, gender, school year, and number of years of studying English.

- Motivation survey. A version modified by Narita (1998), which was originally adapted from the Motivation Questionnaires Battery by Gardener and Lambert (1972), was used to obtain the students' motivational information. The survey consists of 36 Likert-scale items ranging from 1 (strongly agree) to 5 (strongly disagree). The instrument achieved a reliability of 0.86 (Cronbach's alpha).

\section{- $\quad$ Strategy Inventory for Language Learning.}

The original 50-item English version 7.0 of Strategy Inventory for Language Learning for Speakers of Other Languages Learning English (SILL) (Oxford, 1990) was used to measure the students' learning strategies and answer research question part 3). Each item was translated into Japanese, and its accuracy and appropriateness were proof-read by two English-Japanese bilingual scholars. The questionnaire used a five-point Likert-scale ranging from 1 (never or almost never true of me) to 5 (always or almost always true of me), and each item represented a subscale category of one of the following six learning strategies: A) Memory (e.g., "Remembering more effectively," item 1 - 9); B) Cognitive (e.g., "Using all your mental processes," item 10-23); C) Compensation (e.g., "Compensating for missing knowledge," item 24-29); D) Metacognitive (e.g., "Organizing and evaluating your learning," item 30-38); E) Affective (e.g., "Managing your emotions," item 39-44); and F) Social (e.g., "Learning with others," item 45-50). The instrument achieved a reliability of 0.92 (Cronbach's alpha). Oxford (1990) suggested interpreting the level of use based on the following range of average SILL scores:

$\begin{array}{ll}\text { High strategy use } & 3.5-5.0 \\ \text { Medium strategy use } & 2.5-3.4 \\ \text { Low strategy use } & 1.0-2.4\end{array}$

The results of this study are compared to the above scores. 


\section{Results}

\subsection{Read-Aloud Instruction Package and English Proficiency}

The means and standard deviations for the pretest and posttest, and the results of dependent $t$ tests are shown in Table 1. As the Table 1 indicates, both listening and reading scores improved significantly after three months' intensive instruction using the read-aloud instruction package. The listening score increased 9.62 points and the reading score 3.53 points, for a total gain of 13.15 points (from 112.63 to 125.78 ).

Table 1. Pre and posttest comparisons of TOEIC Bridge ${ }^{\circledR}$ score

\begin{tabular}{lllllll}
\hline \multicolumn{2}{c}{ Pretest $(\mathrm{N}=32)$} & \multicolumn{3}{c}{ Posttest $(\mathrm{N}=32)$} \\
\hline Mean & SD & Mean & SD & Post-Pre & t-test \\
\hline Reading Score & 53.97 & 8.13 & 63.59 & 5.9 & 9.62 & $6.03^{*}$ \\
Total Score & 58.66 & 8.15 & 62.19 & 9.03 & 3.53 & $2.64^{*}$ \\
& 112.63 & 12.31 & 125.78 & 12.45 & 13.15 & \\
\hline
\end{tabular}

Note. ${ }^{*} \mathrm{p}<.05, * * \mathrm{p}<.001$.

\subsection{Read-aloud instruction package and student motivation to learn English}

The following Table 2 shows the results of pre and posttests according to each factor of learner motivation. As the results indicate, no significant changes of motivation were found after the instruction. "To communicate with other people" decreased 0.13; "To learn an academic subject in English" decreased 0.01; "To obtain cultural knowledge" decreased 0.02; "To use English as a future career" decreased 0.02; "To meet the expectations of parents" increased 0.13; and "To fulfill graduation requirement" increased 0.20 . However, none of these changes were statistically significant.

Table 2. Pre and Posttest Comparisons of Motivation Inventory

\begin{tabular}{llllll}
\hline & Pretest $(\mathrm{N}=32)$ & \multicolumn{3}{l}{ Posttest $(\mathrm{N}=32)$} \\
\hline t-test & Mean & SD & Mean & SD & t-test \\
\hline A: Communication & 3.82 & 0.63 & 3.69 & 0.83 & -0.88 \\
B: Academic & 2.61 & 0.79 & 2.60 & 0.76 & -0.07 \\
C: Culture & 3.63 & 0.62 & 3.61 & 0.65 & -0.31 \\
D: Career & 3.32 & 0.49 & 3.30 & 0.63 & -0.26 \\
E: Meet the expectation & 3.46 & 0.68 & 3.59 & 0.67 & 1.16 \\
F: Requirement & 2.81 & 1.16 & 3.01 & 1.05 & 0.99 \\
\hline
\end{tabular}

Note. A: To communicate with other people, B: To learn an academic subject in English, e.g., linguistics and literature, C: To obtain cultural knowledge, D: To use English as a tool for future career, E: To meet the expectation of parents, F: To fulfill graduation requirement.

$* \mathrm{p}<.05$.

\subsection{Read-Aloud Instruction Package and Student Learning Strategy for English}

Table 3 shows the results of pretest and posttest of each category of student learning strategy for English as a foreign language. Scores for all strategies fell between 2.5 and 3.4, the range for medium strategy use. Statistically, two out of six categories of student learning strategies changed significantly: "Using all your mental processes" increased 0.23 from pre to posttest and "Learning with others" decreased 0.55 . Although no statistically significant changes were found in the other categories, the raw scores increased from pretest to posttest in all four categories. 
Table 3. Pre and posttest comparisons of learning strategies

\begin{tabular}{llllll}
\hline & Pretest $(\mathrm{N}=32)$ & & Posttest $(\mathrm{N}=32)$ & \\
\hline t-test & Mean & SD & Mean & SD & t-test \\
\hline A: Remembering & 2.81 & 0.49 & 2.93 & 0.57 & 1.40 \\
B: Using mental process & 2.69 & 0.50 & 2.92 & 0.58 & $\mathbf{3 . 3 9 *}$ \\
C: Compensating & 2.76 & 0.62 & 3.00 & 0.59 & 1.84 \\
D: Organizing & 2.59 & 0.63 & 2.77 & 0.53 & 1.73 \\
E: Managing emotions & 2.64 & 0.73 & 2.73 & 0.64 & 0.87 \\
F: Learning with others & 2.83 & 0.71 & 2.28 & 0.90 & $\mathbf{- 3 . 3 0 *}$ \\
\hline
\end{tabular}

Note. A: Remembering more effectively, B: Using all your mental processes, C: Compensating for missing knowledge, D: Organizing and evaluating your learning, E: Managing your emotions, and F: Learning with others. $* \mathrm{p}<.05$.

\section{Discussion}

The current study establishes the effectiveness of the read-aloud instruction package, which is consistent with the study conducted by Shinozuka et al. (2014). Because the instruction is designed to use all sensory motor skills as explained previously, higher scores for the participants on the TOEIC Bridge ${ }^{\circ}$ after the instruction might be related to a change in language processing in the brain. The following sections explain the effectiveness of the instruction from neuro-linguistic and cognitive linguistic viewpoints.

First, we analyzed the basis for effectiveness of S/CRP. In this study, EFL students scored significantly higher on both reading and listening subtests after the instruction. Reading processing requires two different but highly interrelated areas in the first place, word recognition and comprehension, regardless of the language in question. It is clear that difficulty in automatic word identification is significantly associated with an EFL reader's ability to effectively comprehend what s/he is reading (Lyon, 1995; Torgersen, Reshot, \& Alexander, 2001). The ability to recognize individual elements is crucial for reading (James \& Engelhardt, 2012), and improves one's reading skills.

The results are compatible with many previous studies, including findings that S/CRP facilitates reading speed (e.g., Ellis, 2003; Newell, 1990; Nishida, 2009; Ohtagaki \& Ohmori, 1991; Tan \& Nicholson, 1997) and understanding of meaningful sentences/phrases (Nishida, 2013). Nishida (2013) concluded in her research findings that learning chunking is effective in improving EFL learners' reading comprehension and that it also poses more benefits when taught along with phrase/syntactic structures. The results of this study are also consistent with Cathercole and Baddely (1990), who mentioned that repeated slash/chunked reading instruction should be effective in improving phonological loop function in working memory for not only struggling readers of English as a second language, but also people with learning disability/dyslexia.

Second, the basis for the effectiveness of simultaneous read-aloud and write-out practice was considered. This practice forces the participants to conduct input and output simultaneously, that is to say, comprehensible reading aloud as visual input, and writing with correct spelling and speaking with accurate pronunciation as output. The activity also requires maintaining concentration to focus on listening and writing, and to use almost all perceptual motor skills. From neuro-scientific perspectives (Grafton et al., 1992; Jenkins, Brooks, Nixon, Frackowiak, \& Passingham, 1994; Seitz \& Rolan, 1992), using various motor skills simultaneously results in acquiring far better memorization. Many scientists consider the simultaneous and sequential motor action and learning practice to be fairly similar to cognitive rehabilitation and kinetic movement for patients with brain injury when it comes to visual-spatial and linguistic function domains in the cerebral cortex (Müller, Kleinhans, Pierce, Kemmotsu \& Counchnsens, 2002; Schaechter, 2004; Potgieser, van der Hoorn, \& de Jong, 2005). These various forms of input as stimuli and output as response seem to eventually strengthen cognitive language processing as it is reinforced in the brain. Consequently, similar to cognitive and kinetic rehabilitation, the repeated simultaneous read-aloud and write-out practice would lead to improving English skills (Müller, Kleinhans, Pierce, Kemmotsu \& Counchnsens, 2002; Schaechter, 2004; Potgieser, van der Hoorn, \& de Jong, 2005).

Third, the basis for effectiveness of reading aloud was investigated. Unlike silent reading (subvocal reading/inner speech), reading aloud obliges the reader to vocalize reading materials, which includes accurate stress, rhythm, 
tone, and intonation. The EFL students were instructed to pay attention to these prosodic aspects of language. Miyasako (2008) found a positive relationship between the level of reading comprehension and reading aloud skill. Kadota (1982) explained that repeated reading aloud practice enhanced automatic language processing and improves English reading skills because the reading aloud practice requires the reader to concentrate on comprehending the contents of what $\mathrm{s} / \mathrm{he}$ is reading. He also mentioned that the practice is beneficial for much faster speech coding and internalizing reading skills, including knowledge of grammar and vocabulary. As a result, silent reading speed improved as well as grammar and vocabulary knowledge.

The effectiveness of reading aloud poses implications not only for EFL learners, but also for L1 students, especially those who have difficulty with reading comprehension. Considering the benefits of reading aloud, it was reported that elementary school children in the U.S. were able to build automaticity of word recognition and acquire the proper prosodic aspects of English as EFL learners did (Kuhn et al, 2006; National Reading Panel, 2000). Fuchs et al. (2001) proclaimed that being able to read aloud with accurate prosodic aspects could be one of the indicators of reading comprehension ability.

Fourth, regarding the effectiveness of cloze tests, the tests are considered a useful tool for measuring levels of reading comprehension and text readability for native English speakers (Alderson, 1980; Readance, J. E., Balwin, R. S., Bean, T. W., \& Dishner, E. K., 1980), as well as for ESL/EFL learners (Aitken, 1977; Bialystok \& Howard 1979; Oller, 1976). The most recent study also showed that cloze test practice improved English grammatical accuracy for Iranian EFL learners at the intermediate level (Mashhadi \& Bagheri, 2015). Aitken (1977) mentioned that the majority of studies show that cloze performance correlates significantly with other measures of L2 proficiency. Additionally, in a cloze test, the participants need to implement a large number of interrelated skills which are composed of a language system (e.g., lexical, grammatical, and contextual) in order to predict and analyze accurately what word most appropriately fits into each empty space using the brain. It is reasonable to say that a series of cognitive, challenging, and arduous inference skills (Bialystok \& Howard, 1979) are required when making an effort to fill in the blanks of cloze tests, effectively contributing to the improvement of L2 skills. Thus, by adopting cloze tests in the instruction package, the EFL learners' awareness of English skills might have improved, resulting in higher posttest scores.

Fifth, we carefully examined the influence that the read-aloud instruction package had on students' motivation to learn English. Motivation is regarded as one of the crucial factors in successful learning outcomes, and many previous studies have demonstrated that EFL learners with higher proficiency tend to show stronger motivation (e.g., Gan, Humphreys, \& Hamp-Lyons, 2004). It was also reported that some intensive instruction, such as group activities and shadowing practice, enhanced students' intrinsic motivation (Hiromori \& Tanaka, 2006; Kato, 2012). Therefore, it was expected that the read-aloud instruction package would increase some of the factors of motivation and raise English proficiency. However, no significant change was found in any factors of motivation after three months of instruction using the read-aloud instruction package. One possible reason for this might be insufficient length of instruction. Three months of instruction can improve EFL students' learning outcomes of English, but it may be inadequate to change their level of motivation. Another possible explanation is the content of instruction. Unlike the studies by Hiromori \& Tanaka (2006) and Kato (2012), the read-aloud instruction package was designed to improve EFL students' English proficiency, but was not designed to promote their motivation. According to Deci and Ryan (1985), the three psychological needs, i.e., competence, autonomy, and psychological relatedness motivate the learners. Perhaps, appropriate and relevant class activities which incorporate these three needs should be included in the instruction package to promote students' motivation. For example, communicative activities with native speakers might be effective in promoting motivation to communicate, and inviting professionals in the front lines as guest speakers might inspire students and eventually increase a motivation factor related to careers, etc.

Finally, the influence of the read-aloud instruction on student learning strategies for English was also discretely examined. The results showed that the learning strategy of using mental processes in learning increased significantly, while learning with other people decreased, and no changes were found in the other categories after the instruction. "Using mental processes" probably increased because the various activities which promoted use of mental processes were included in the instruction. Learning with other people probably decreased not because the EFL learners lost interest in learning with others, but because the instruction required more individual, independent study and encouraged autonomy and self-management of study plans. The current study also found a pattern of EFL students' use of learning strategies among Japanese college students whose English proficiency was elementary level. Frequency of their use of the six categories of learning strategies ranged from 2.5 to 3.0 out of 5.0, which is on the low side of medium frequency of use. Many previous studies agree that learning strategy use differs depending on the students' level of language proficiency. They have found that students of advanced-level 
proficiency use overall strategies more often than students with lower-level proficiency (e.g., Baker \& Boonkit, 2004; Gharbavi \& Seyyed, 2012). Considering the low level of English proficiency of the participants in this study, the result of low medium use of learning strategies is consistent with these previous findings.

\section{Summary and Limitations of Research}

The initial purpose of this project was to provide an effective instruction for EFL students at the elementary level of English using the read-aloud instruction package which was created by Shinozuka et al. (2014). The study demonstrates that the instruction successfully improved students' English proficiency in both listening and reading sub skills, which supports the earlier study by Shinozuka et al. (2014). In sum, it is reasonable to conclude that the read-aloud instruction package was effective regardless of EFL students' learning strategies, and this is because the instruction package included various activities which promoted all sensory-motor skills and accommodated various types of learning styles. It is recommended to include a variety of extra-curricular activities in the instruction to promote their motivation and enthusiasm to learn English, as well as to encourage to use various L2 learning strategies.

There are a number of limitations in this study. First, the pattern of EFL student use of learning strategies was examined only for the elementary level of English. Comparison with Intermediate and Advanced level of EFL learners' groups could be conducted for better understanding of the use of learning strategies for English among Japanese college students. Second, this study utilized Oxford's SILL (Oxford, 1990) as a measurement of learning strategy. Repetitive verification of the results using other instruments is necessary, considering the recent criticism regarding the validity of translated versions of SILL, especially in an ideographic language such as Japanese (Gao, 2004).

Additionally, in order to thoroughly and scientifically investigate the neural basis for this read-aloud instruction package, experiments using neuroimaging machines such as fMRI (functional Magnetic Resonance Imaging), PET (Positron Emitting Tomography) and fNIRS (functional Near Infrared Spectroscopy) should be carried out to determine how brain activation and function will be changed before and after the instruction package.

\section{Acknowledgement}

We are deeply grateful to the anonymous reviewers for correction of the manuscript and their precious comments. We would also like to thank each participant who generously shared their time for this research. Without their generous help, this research could not have been accomplished.

\section{References}

Aitken, K. (1977). Using cloze procedure as an overall language proficiency test. TESOL Quarterly, 11, 59-67. https://doi.org/10.2307/3585592

Akbari, R. (2003). The relationship between the use of language learning strategies by Iranian learners of English, their foreign language proficiency, and the learners' IQ scores. IJAL, 6, 1-20.

Alderson, J. (1979). The cloze procedure and proficiency in English as a foreign language. TESOL Quarterly, 13(2), 219-227. https://doi.org/10.2307/3586211

Alderson, J. (1980). Native and non-native speaker performance on cloze tests. Language Learning, 30, 59-76. https://doi.org/10.1111/j.1467-1770.1980.tb00151.x

Alhaisoni, E. (2012). Language learning strategy use of Saudi EFL students in an intensive English learning context. Asian Social Science, 8(13), 115-127. https://doi.org/10.5539/ass.v8n13p115

$\mathrm{Au}, \mathrm{S}$. Y. (1988). A critical appraisal of Gardner's social-psychological theory of second-language (L2) learning. Language Learning, 28(1), 55-68. https://doi.org/10.1111/j.1467-1770.1988.tb00402.x

Ayabe, Y., Kano, F., \& Ito, K. (1995). Daigakusei no nihongo gakushu dooki ni kansuru kokusai choosa: New Zealand no baai [International survey of motivation to study Japanese among university students: In case of New Zealand]. Nihongo Kyoiku, 86, 162-172.

Bachman, L. F. (1982). The trait structure of cloze test scores. TESOL Quarterly, 16(1), 61-70. https://doi.org/10.2307/3586563

Bachman, L. F. (1985). Performance on cloze tests with fixed-ratio and rational deletions. TESOL Quarterly, 19(3), 535-556. https://doi.org/10.2307/3586277

Baddeley, A. D. (1986). Working memory. Oxford: Oxford University Press.

Baddeley, A. D. (1998). Human memory: Theory and practice (Revised Ed.). New York: Allyn and Bacon. 
Baddeley, A. D. (1999). Essentials of human memory. Hover: Psychology Press.

Baker, W., \& Boonkit, K. (2004). Learning strategies in reading and writing: EAP contexts. Regional Language Centre Journal, 35(3), 295-326. https://doi.org/10.1177/0033688205052143

Bialystok, E. \& Howard, J. (1979). Inferencing as an aspect of cloze test performance. Working Papers on Bilingualism, 17, 24-36.

Brown, R.A. (2004). Motivation for learning English among Japanese University students. Information \& Communication Studies, 31, 1-12.

Carhart, R. (1950). Clinical application of bone conduction audiometry. Archives of otolaryngology, 51(6), 798-808. https://doi.org/10.1001/archotol.1950.00700020824003

Casteel, C. A. (1988). Effects of chunked reading among learning disabled students: An experimental comparison of computer and traditional chunked passages. Educational Technology Systems, 17(2), 115-121. https://doi.org/10.2190/EBNP-6Q4W-1BJW-G5HM

Cathercole, S. E., \& Baddeley, A. D. (1990). Phonological memory deficits in language disordered children: Is there a causal connection? Journal of Memory and Language, 29, 336-390. https://doi.org/10.1016/0749-596X(90)90004-J

Chang, A. C. (2012). Improving reading rate activities for EFL students: Timed reading and repeated oral reading. Reading in a Foreign Language, 24(1), 56-83.

Cheng, H., \& Dörnyei, Z. (2003). The use of motivational strategies in language instruction: The case of EFL teaching in Taiwan: Innovation in language. Learning and Teaching, 1, 153-174.

Chiswick, B. R., \& Miller, P. W. (2004). Linguistic distance: A quantitative measure of the distance between English and other languages. IZA Discussion Paper, No. 1246.

Darnell, D. K. (1968). The development of an English language proficiency test of foreign students using a clozentropy procedure. Final Report. Colorado University, Boulder. DHEW Bureau No. BP-7-H-010.

Deci, E. L., \& Ryan, R. M. (1985). Intrinsic motivation and self-determination in human behavior. New York: Plenum. https://doi.org/10.1007/978-1-4899-2271-7

Diaz-Maggioli, G. (2004). Teacher-centered professional development. Virginia: ASCD.

Dörnyei, Z. (1994). Motivation and motivating in the foreign language classroom. The Modern Language Journal, 78(3), 273-284. https://doi.org/10.1111/j.1540-4781.1994.tb02042.x

Dornyei, Z., \& Csizer, K. (1998). Ten commandments for motivating language learners: Resutls of an empirical study. Language Teaching Research, 2, 203-229. https://doi.org/10.1177/136216889800200303

Ellis, N. C. (2003). Constructions, chunking, and connectionism: The emergence of second language structure. In C. Doughty, \& M. Long (Eds.), The handbook of second language acquisition (pp. 63-103). Malden, MA: Blackwell Publishing Ltd. https://doi.org/10.1002/9780470756492.ch4

Ely, C. M. (1986). Language learning motivation: A descriptive and causal analysis. The Modern Language Journal, 70(1), 28-35. https://doi.org/10.1111/j.1540-4781.1986.tb05240.x

ETS. (2010). Test and Score data summary for TOEFL internet-based and paper-based tests. Retrieved from https://www.ets.org/Media/Research/pdf/TOEFL-SUM-2010.pdf

Fodor, J. A., Bever, T. G., \& Garrett, M. F. (1974). The psychology of language. New York: McGraw-Hill.

Fuchs, L., Fuchs, D., \& Hosp, M. (2001). Oral reading fluency as an indicator of reading competence: A theoretical, empirical and historical analysis. Scientific Studies of Reading, 5, 239-256. https://doi.org/10.1207/S1532799XSSR0503_3

Gan, Z., Humphreys, G., \& \& Hamp-Lyon, L. (2004). Understanding successful and unsuccessful EFL students in $\begin{array}{lllll}\text { Chinese Universities. } & \text { Foreign } & \text { Language 229-244. }\end{array}$ https://doi.org/10.1111/j.0026-7902.2004.00227.x

Gao, X. (2004). A critical review of questionnaire use in learner strategy research. Prospect, 19(3), 3-14.

Gardner, R. C. (1985a). The attitude/motivation test battery: Technical report. Ontario, Canada: University of Western Ontario, Department of Psychology.

Gardner, R. C. (1985b). Social psychology and second language learning: The role of attitudes and motivation. London: Edward Arnold. 
Gardner, R. C., \& Lambert, W. E. (1972). Attitudes and motivation in second language learning. Rowley, MA: Newbury.

Grafton, S. T, Mazziotta, J. C., Presty, S., Friston, K. J., Frackowiak, R. S., \& Phelps, M. E. (1992). Functinal anatomy of human procedural learning determined with reginal cerebral blood flow and PET. Journal of Neuroscience, 12, 2542-2548.

Griffiths, C. (2003). Patterns of language learning strategy use. System, 31, 367-383. https://doi.org/10.1016/S0346-251X(03)00048-4

Ghafournia, N. (2014). Language learning strategy use and reading achievement. English Language Teaching, 7(4), 64-73. http://dx.doi.org/10.5539/elt.v7n4p64

Ghani, K. A., Mahfuz, M. S., Saad, A. J. M., \& Yusoff, N. M. R. N. (2014). Relationship between the usage of language learning strategies and the level of proficiency in learning Arabic ab initio. Asian Social Science, 10(9). http://ex.doi.org/10.5539/ass.v10n9p262

Gilbert, A. C., Boucher, V. J., \& Jemel, B. (2014). Perceptual chunking and its effect on memory in speech processing: ERP and behavioral evidence. Frontiers in Psychology, 5, 1-9. https://doi.org/10.3389/fpsyg.2014.00220

Grabe, W., \& Stoller, F. L. (2011). Teaching and Researching Reading (2nd Ed.). New York: Longman.

Green, J. M., \& Oxford, R. L. (1995). A closer look at learning strategies, L2 proficiency, and gender. TESOL Quarterly, 29(2), 261-297. https://doi.org/10.2307/3587625

Gharbavi, A. \& Seyyed, A. M. (2012). Do Language proficiency levels correspond to language learning strategy adoption? English Language Teaching, 5(7), 111-122. http://dx.doi.org/10.5539/elt.v5n7p110

Hiromori, T., \& Tanaka, H. (2006). Instructional intervention on motivating English learners: The self-determination theory view point. Language Education and Technology, 43, 111-126.

Hook, P. E., \& Jones, S. D. (2002). The importance of automaticity and fluency for efficient reading comprehension. The International Dyslexia Association Quarterly Newsletter, 28(1), 9-14.

IELTS. (2015). Task taker performance 2015. Retrieved August 10, 2016 from https://www.ielts.org/teaching-and-research/test-taker-performance.

James, K. H., \& Engelhardt, L. (2012). The effects of handwriting experience on functional brain development in pre-literate children. Trends in Neuroscience and Education, 1(1), 32-42. https://doi.org/10.1016/j.tine.2012.08.001

Japan Today. (2014). Japan ranks 26 th of 60 countries in global English proficiency. Retrieved July 10, 2014, from $\mathrm{http} / /$ www.japantoday.com/category/national/view/japan-ranks-26th-of-60-countries-in-global-english-prof iciency-index

Jenkins, I. H., Brooks, D. J., Nixon, P. D., Frackowiak, R. S., \& Passingham, R. E. (1994). Motor sequence learning: a study with positron emission tomography. Journal of Neuroscience, 14, 3775-3790.

Jones, G. (2012). Why chunking should be considered as an explanation for developmental change before short-term memory capacity and processing speed. Frontiers in Psychology, 3, 1-8. https://doi.org/10.3389/fpsyg.2012.00167

Jongsma, E. (1971). The cloze procedure as a teaching technique. Newark: The International Reading Association.

Just, M. A., \& Carpenter, P. A. (1987). The psychology of reading and language comprehension. Newton, MA: Allyn \& Bacon.

Kadota, S. (1982). Some psycholinguistics experiments on the process of reading comprehension. Journal of Assumption Junior College, 9, 49-70.

Kato, S. (2012). A study of intrinsic motivation and learning activities. Gengo Bunka Ronso, 6, 9-22.

Kaufman, E. K., Robinson, J. S., Bellah, K. A., Akers, C., Haase-Wittler, P., \& Martindale, L. (2008). Engaging students with brain-based learning. Techniques (ACTE), 83(6), 50-55.

Khamkhien, A. (2010a). Factors affecting language learning strategy reported usage by Thai and Vietnamese EFL learners. Electronic Journal of Foreign Language Teaching, 7(1), 66-85.

Khamkhien, A. (2010b). Teaching English Speaking and English speaking tests in the Thai Context: A reflection 
from Thai perspective. English Language Teaching, 3(1), 184-190. http://dx.doi.org/10.5539/elt.v3n1p184

Kiroglu, K., \& Demirei, M. (2012). Chunked texts in reading class: The case of Turkish learners of English. Pamukkale Universitesi Egitim Fakultesi Dergisi, 32, 65-76.

Kowal, S., O’Connell, D. C., O’Brien, E. A., \& Bryant, E. T. (1975). Temporal aspects of reading aloud and speaking: Three experiments. The American Journal of Psychology, 88(4), 549-569. https://doi.org/10.2307/1421893

Kuhn, M. R., Schwanenflugel, P. J., Morris, R. D., Morrow, L. M., Woo, D. G., Meisinger, E. B., Sevcik, R. A., Bradley, B. A., \& Stahl, S. A. (2006). Teaching children to become fluent and automatic readers. Journal of Literacy Research, 38(4), 357-387. https://doi.org/10.1207/s15548430jlr3804_1

Kunihiro, M. (1970). Eigo no Hanashikata [How to speak English]. Tokyo: Saimaru Shuppan.

Lai, Y. (2009). Language learning strategy use and English proficiency of University freshmen in Taiwan. TESOL Quarterly, 43(2), 255-280. https://doi.org/10.1002/j.1545-7249.2009.tb00167.x

Lengkanawati, N. S. (2004). How learners from different cultural backgrounds learn a foreign language? The Asian EFL Journal. Abstract retrieved April 20, 2015, from http://asian-efl-Journal-com/1363/quarterly-journal/2004/03/how-learners-from-different-cultural-backgrou nds-learn-a-foreign-language/

Lenneberg, E. H. (1967). Biological foundations of language. New York: Wiley.

Lyon, G. R. (1995). Toward a definition of dyslexia. Annals of Dyslexial, 45(1), 1-27. https://doi.org/10.1007/BF02648210

Mashhadi, F., \& Bagheri, A. (2015). The effect of cloze test practice on grammatical accuracy: Cooperative versus individual perspective in focus. Journal of Applied Linguistics and Language Research, 2(5), 74-83.

Ministry of Education, Culture, Sports, Science and Technology. (2013). Guroobaruka ni taioo- shita eigo kyooiku kaikaku jisshi keikaku [English educational reform plan to deal with globalization]. Retrieved August 2, 2014 from http://www.mext.go.jp/b_menu/houdou/25/12/icsFiles/afieldfile/2013/12/17/1342458_01_1.pdf

Miyahara, F., Namoto, M., Yamanaka, S., Murakami, R, Kinoshita, M., \& Yamamoto, H. (1997). Konomamade yoika daigaku eigo kyoiku [Current status of university English education: Comparison of university students' ability in English and learning behavior in China, Korea, and Japan]. Tokyo: Shohakusha.

Miyasako, N. (2008). Is the Oral Reading Hypothesis valid? Language Education and Technology, 45, 15-34.

Moldasheva, G., \& Mahmood, M. (2014). Personality, learning strategies, and academic performance: Evidence from post-Soviet Kazakhstan. Education and Training, 55(4), 343-359. https://doi.org/10.1108/ET-10-2012-0101

Müller R. A., Kleinhans, N., Pierce, K., Kemmotsu, N., \& Courchesne, E. (2002). Function MRI of motor sequence acquisition: effects of learning stage and performance. Brain Cognitive Research, 14, 227-293. https://doi.org/10.1016/S0926-6410(02)00131-3

Murray, B. (2010). Students' language learning strategy use and achievement in the Korean as a foreign language classroom. Foreign Language Annals, 43(4), 624-634. https://doi.org/10.1111/j.1944-9720.2010.01105.x

Narita, T. (1998). The relations between motivations and examination scores: The case of university students in Thailand. Sekaino Nihongo-kyooiku, 8, 1-11.

National Reading Panel. (2000). Report of the subgroups: National Reading Panel. Washington, DC: National Institute of Child Health and Development.

Newell, A. (1990). United theories of cognition. Cambridge: Harvard University Press.

Nishida, H. (2009). Comparison of reading aloud, chunking, and grammar as instruction techniques for reading comprehension. Kwansai Review, 25/26, 21-30.

Nishida, H. (2013). The influence of chunking on reading comprehension: Investigating the acquisition of chunking skill. The Journal of Asia TEFL, 10(4), 163-183.

Ohtagaki, M., \& Ohmori, T. (1991). The advantage of 'progressive' reading activities using sense groups for Japanese English learners: An experimental study. ARELE, 2, 83-92.

Oller, J., Jr. (1976). A program for language testing research. Language Learning, Special Issue 4, 141-166.

Oller, J., Jr. (1972). Scoring methods and difficulty levels for cloze tests of ESL proficiency. Modern Language 
Journal, 56, 151-158. https://doi.org/10.1111/j.1540-4781.1972.tb05035.x

Oller, J., Jr., Hudson, A., \& Liu, P.F. (1977). Attitudes and attained proficiency in ESL: A sociolinguistic study of native speakers of Chinese in the U.S. Language Learning, 27(1), 1-27. https://doi.org/10.1111/j.1467-1770.1977.tb00289.x

O’Malley, M. J., Chamot, A., Stewner-Manzanares, G., Kupper, L. \& Russo, R. P. (1985). Learning strategies used by beginning and intermediate ESL students. Language Learning, 35(1), 21-44. https://doi.org/10.1111/j.1467-1770.1985.tb01013.x

Oxford, R. L. (1990). Language learning strategies. Boston, MA: Heinle \& Heinle publishers.

Oxford, R., \& Ehrman, M. (1995). Adult's language learning strategies in an intensive foreign language program in the United States. System, 23(4), 359-385. https://doi.org/10.1016/0346-251X(95)00023-D

Oxford, R. L., \& Nyikos, M. (1989). Variables affecting choice of language learning strategies by university $\begin{array}{lllll}\text { students. The Modern } & \text { 291-300. }\end{array}$ https://doi.org/10.1111/j.1540-4781.1989.tb06367.x

Oxford, R. L., \& Shearin, J. (1994). Language learning motivation: Expanding the theoretical framework. The Modern Language Journal, 78(1), 12-28. https://doi.org/10.1111/j.1540-4781.1994.tb02011.x

Purpura, J. E. (1997). An analysis of the relationships between test takers' cognitive and metacognitive strategy use and second language test performance. Language Learning, 47(2), 289-325. https://doi.org/10.1111/0023-8333.91997009

Pishghadam, R. (2009). A quantitative analysis of the relationship between emotional intelligence and foreign language learning. Electronic Journal of Foreign Language Teaching, 6(1), 31-41.

Pontart, V., Bidet-Lldei, C., Lambert, E., Morisset, P., Flouret, L., \& Alamargot, D. (2013). Influence of handwriting skills during spelling in primary and lower secondary grades. Frontiers in Psychology, 4. http://dx.doi.org/10.3389/fpsyg.2013.00818

Porter, P. A. (1983). Variations in the conversations of adult learners of English as a function of the proficiency level of the participants. (Doctoral dissertation). Stanford University, CA.

Potgieser, A. R. E., van der Hoorn, A. \& de Jong, B. M. (2015). Cerebral activations related to writing and drawing with each hand. PLos ONE, 10(5). http://dx.doi.org/10.1371/0126723

Ransinki, T. V., Padak, N. D., McKeon, C. A., Wilfong, L. G., Friedauer, J. A., \& Heim, P. (2005). Is reading fluency a key for successful high school reading? Journal of Adolescent \& Adult Literacy, 49(1), 22-27. https://doi.org/10.1598/JAAL.49.1.3

Readance, J. E., Balwin, R. S., Bean, T. W., \& Dishner, E. K. (1980). Field dependence independence as a variable in cloze test performance. Journal of Reading Behavior, 12(1), 65-67. https://doi.org/10.1080/10862968009547353

Riazi, A. (2007). Language learning strategy use: Perceptions of female Arab English majors. Foreign Language Annals, 40(3), 433-440. https://doi.org/10.1111/j.1944-9720.2007.tb02868.x

Rivera-Mills, S., \& Plonsky, L. (2007). Empowering students with language learning strategies: A critical review of current issues. Foreign Language Annals, 40(3), 373-559. https://doi.org/10.1111/j.1944-9720.2007.tb02874.x

Robinson, R. D. (1972). An introduction to the cloze procedure: An annotated bibliography. Newark: The International Reading Association.

Schaechter, J. D. (2004). Motor rehabilitation and brain plasticity after hemiparetic stroke. Progress in Neurobiology, 73(1), 61-72. https://doi.org/10.1016/j.pneurobio.2004.04.001

Schreiber, P. A., \& Read, C. (1980). Children's use of phonetic cues in spelling, parsing, and maybe reading. Bulletin of the Orton Society, 30, 209-224. https://doi.org/10.1007/BF02653719

Schwanenflugel, P. J., Harnishleger, K. K., \& Stowe R. W. (1988). Context availability and lexical decisions for abstract and concrete words. Journal of Memory and Language, 27, 499-520. https://doi.org/10.1016/0749-596X(88)90022-8

Seitz, R. J., \& Rolan, P. E. (1992). Learning of sequential finger movements in man: A combined kinematic and positron emission tomography (PET) Study. European Journal of Neuroscience, 4, 154-156. https://doi.org/10.1111/j.1460-9568.1992.tb00862.x 
Shinozuka, K., Mizusawa, Y., \& Shibata, S. (2014). Effectiveness of read-aloud instruction of English for the introductory level Japanese college students. Media English Education Journal, 4, 161-179.

Smith, M. S. (1981). Consciousness-raising and the second language learner. Applied linguistics, 2(2), 159-168. https://doi.org/10.1093/applin/II.2.159

Srisupha, R. (2012). Thai students' language learning strategies. Quarterly Journal of Chinese Studies, 2(2), 53-67.

Stoddard, K., Valcante, G., Sindelar, P., \& Algozzine, B. (1993). Increasing reading rate and comprehension: The effects of repeated readings, sentence segmentation and intonation training. Reading Research and Instruction, 32, 53-65. https://doi.org/10.1080/19388079309558133

Tan, A., \& Nicholson, T. (1997). Flashcards revisited: Training poor readers to read words faster improves their comprehension of text. Journal of Educational Psychology, 89(2), 276-288. https://doi.org/10.1037/0022-0663.89.2.276

Tandoc Jr., J. P. \& Tandoc-Juan, M. V. (2014). Students' personality traits and language learning strategies in English. Journal of Arts, Science \& Commerce, 5(3), 1-10.

Torgensen, J. K., Rashotte, C. A., \& Alexander, A. (2001). Principles of fluency instruction in reading: Relationships with established empirical outcomes. In M. Wolf (Ed.), Dyslexia, fluency and the brain (pp. 333-355). Parkton, MD: York Press.

Taylor, W. (1953). Cloze procedure: a new tool for measuring readability. Journalism Quarterly, 30, 415-453.

Wakamoto, N. (2009). Introversion and extroversion in foreign language learning. New York: Peter Lang AG.

Wharton, G. (2000). Language learning strategy use of bilingual foreign language learners in Singapore. Language Learning, 50(2), 203-244. https://doi.org/10.1111/0023-8333.00117

Yashima, T. (2000). Orientations and motivations in foreign language learning: A study of Japanese college students. JACET Bulletin, 31, 121-133.

Yoshida, K. (2009). Gogaku gakushu niokeru dookizukeni kansuru ichiousatsu [A study of motivation in foreign language learning]. Journal of Environmental Information of Musashi Industorial Univeristy, 10, 108-113.

Zafar, S., \& Meenakshi, K. (2012). A study on the relationship between extroversion-introversion and risk-taking in the context of second language acquisition. International Journal of Research Studies in Language Learning, 1(1), 33-40. http://dx.doi.org/10.5861/ijrsll.2012.vli1.42

Note 1. Bone conduction is defined as the conduction sensor of sound to the inner ear via the bones of the skull (Carhart, 1950).

\section{Copyrights}

Copyright for this article is retained by the author(s), with first publication rights granted to the journal.

This is an open-access article distributed under the terms and conditions of the Creative Commons Attribution license (http://creativecommons.org/licenses/by/4.0/). 